\title{
IN VITRO BIO-INTERACTIVITY OF MTA MIXED WITH DIFFERENT ACCELERANT SOLUTIONS
}

\author{
Suzan Abdul Wanees Amin*
}

\begin{abstract}
Aim: To evaluate and compare the biointeractivity (calcium and hydroxyl ion release into the leachate) of mineral trioxide aggregate (MTA) mixed with three different accelerant solutions.

Methods: MTA was mixed with 5\% calcium chloride (Group $\boldsymbol{C L}$ ), 15\% disodium hydrogen orthophosphate (Group $\mathbf{N a P}$ ), $0.1 \%$ citric acid (Group $\boldsymbol{C A}$ ) or distilled water (Group $\boldsymbol{D W}$ ) as control; each group comprised ten specimens $(n=10)$. The specimens were prepared by packing the mixtures into plastic tubes, $1.5 \mathrm{~mm}$ in internal diameter and $10 \mathrm{~mm}$ in length. Each specimen was immersed in $10 \mathrm{ml}$ deionized water. The calcium ion release and $\mathrm{pH}$ were measured in the leachate after 24,72 and $168 \mathrm{~h}$ of material immersion using an atomic absorption spectrophotometer and a digital $\mathrm{pH}$-meter respectively. Data were analysed using 2-way analysis of variance (ANOVA) with repeated measures, 1-way ANOVA and Tukey post hoc test; p-values less than 0.05 indicated statistical significance $(\mathrm{p}<0.05)$.
\end{abstract}

Results: The accelerant type and time significantly influenced both calcium ion release and $\mathrm{pH}(\mathrm{p}<0.001)$. Overall, Group $\boldsymbol{C} \boldsymbol{L}$ showed the highest calcium ion release followed by Group $\boldsymbol{C A}$ ( $p<0.05$ compared to each other and to Groups $\boldsymbol{D W}$ and $\mathbf{N a P}$ ) then came Groups $\boldsymbol{D W}$ and $\mathbf{N a P}$; there was no difference between the latter two groups $(\mathrm{p}>0.05)$. Group $N a P$ showed the highest leachate $\mathrm{pH}$ compared to Group $\boldsymbol{D W}$ at all time points. In general, calcium ion release and $\mathrm{pH}$ decreased over the 168-hour duration.

Conclusions: Within the conditions of this study, it could be concluded that, among the used MTA accelerants, $5 \%$ calcium chloride solution could yield the highest calcium ion release, while $15 \%$ disodium hydrogen orthophosphate solution may have the highest alkalizing activity; such accelerants could provide MTA with enhanced biointeractive qualities besides accelerating its setting.

KEYWORDS: Mineral trioxide aggregate; biointeractivity; accelerant; calcium chloride; $\mathrm{Na}_{2} \mathrm{HPO}_{4}$; citric acid.

* Associate Professor of Endodontics, Faculty of Dentistry, Cairo University 


\section{INTRODUCTION}

Calcium silicate cements (CSCs), e.g. mineral trioxide aggregate (MTA), are bioactive materials that have become widely used to repair the root and seal the pulp space from the external environment through different clinical applications ${ }^{(1,2)}$. This is due to MTA's several favourable properties including its biointeractivity (ability to release calcium and hydroxyl ions), bioactivity and biocompatibility which result in good sealing ability, antimicrobial activity, and the ability to promote hard-tissue formation creating biological seal ${ }^{(1-5)}$.

On hydration, MTA reacts with water to form two main products, namely calcium silicate hydrate gel and calcium hydroxide ${ }^{(2,6)}$. The dissociation of calcium hydroxide in the surrounding humid environment leads to calcium ion release and hydroxyl radicle release creating an alkalizing effect $(2,4-8)$; such chemical interplay with the surrounding is favourable for creating biological barriers and controlling local infection ${ }^{(3,9-11)}$.

Some of MTA's properties, however, still require enhancement among which is its setting time. The reported setting time of MTA in the endodontic literature is approximately 3 hours, yet, could reach up to 72 hours ${ }^{(1,9,12,13)}$. Such long setting time could expose the material to the risk of material washout in some clinical applications, e.g. as a root-end filling or root repair material in periradicular surgeries, or on irrigation of an area with a freshly-compacted material; such risk would imply favouring a multiple-visit approach ${ }^{2}, 9,12,14$, ${ }^{15)}$. The slow set, also, contributes to the challenging handling characteristics of the material ${ }^{(9)}$.

Several setting-reaction accelerants for MTA have been investigated ${ }^{(9,12,16-19)}$. Calcium chloride $\left(\mathrm{CaCl}_{2}\right)$ has been the most-commonly-used accelerant with different forms and concentrations being used ${ }^{(1,20,21)}$. Other MTA accelerators have, also, been investigated e.g. 15\% disodium hydrogen orthophosphate $\left(\mathrm{Na}_{2} \mathrm{HPO}_{4}\right)$, also called sodium phosphate dibasic, ${ }^{(17,18)}$ and low-dose citric acid $(0.1 \%)^{(19)}$. The use of such accelerants, however, can alter other physico-chemical or mechanical

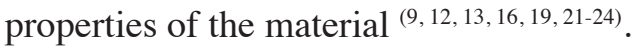

Several studies have assessed the biointeractivity of MTA ${ }^{(1,4,5,13,15,23,25-28)}$; few of which, however, assessed the effect of accelerators on the calcium ion release and $\mathrm{pH}$ of the soaking water of MTA (its leachate $)^{(15,13,23)}$. The objective of this study, thus, was to evaluate and compare the effect of three MTA accelerant solutions $\left(5 \% \mathrm{CaCl}_{2}, 15 \% \mathrm{Na}_{2} \mathrm{HPO}_{4}\right.$, and $0.1 \%$ citric acid) on the calcium ion release and the $\mathrm{pH}$ (alkalizing activity) of the leachate.

\section{MATERIALS AND METHODS}

\section{Materials}

In this study, MTA (Angelus Indústria de Produtos Odontológicos S/A, Londrina, Brazil) was mixed with each of the three accelerant solutions: $5 \% \mathrm{CaCl}_{2}, 15 \% \mathrm{Na}_{2} \mathrm{HPO}_{4}$ or $0.1 \%$ citric acid; mixing with sterile, distilled water was used as control. A chemist used each of the following powders: calcium chloride $\left(\mathrm{CaCl}_{2}\right.$; Al-Alamia for Chemical Industries, ARE), di-sodium hydrogen orthophosphate anhydrous $\left(\mathrm{Na}_{2} \mathrm{HPO}_{4} ;\right.$ Oxford Laboratory Chemicals, Thane, India) and citric acid monohydrate (Oxford Laboratory Chemicals, Thane, India) with distilled water for the preparation of their corresponding solutions.

\section{Preparation of the specimens}

MTA powder was hand-mixed with sterile, distilled water according to the manufacturer's instructions (control). Mixtures of MTA with the accelerator solutions were done with the same consistency as the control. Mixing was done using a stainless steel cement spatula on a clean glass slab; both kept at room temperature $\left(25^{\circ} \mathrm{C}\right)$ for $24 \mathrm{~h}$.

Specimens were prepared by inserting each fresh mixture into plastic tubes, $1.5 \mathrm{~mm}$ in internal 
diameter and $10 \mathrm{~mm}$ in length corresponding to an exposed surface area of $3.53 \mathrm{~mm}^{2}$, with both ends open. An amalgam carrier was used to place the mixture into the tubes then the mixture was compacted using endodontic pluggers (Roeko, Coltène/ Whaledent, USA) with the tubes vertically supported on the glass slab. Ten specimens were prepared for each of the following groups according to the mixture type $(n=10)$ : Group $(\boldsymbol{D W})$, MTA+ distilled water (control); Group (CL), MTA $+5 \%$ $\mathrm{CaCl}_{2}$ solution; Group (NaP), MTA+15\% $\mathrm{Na}_{2} \mathrm{HPO}_{4}$ solution; and Group $(\boldsymbol{C A}), \mathrm{MTA}+0.1 \%$ citric acid solution.

After initial setting of the material, each specimen was individually immersed in $10 \mathrm{ml}$ deionized water $(\mathrm{pH}=6.9)$ in a sealed, polypropylene tube and gently shaken then stored at $37^{\circ} \mathrm{C}{ }^{(29)}$. The leachate for the following durations was collected: 0 to $24 \mathrm{~h}$ (considered the $24 \mathrm{~h}$ time point/ $24 \mathrm{~h}$ from mixing), 24 to $72 \mathrm{~h}$ (considered the $72 \mathrm{~h}$ time point $/ 72 \mathrm{~h}$ from mixing) and 72 to $168 \mathrm{~h}$ (considered the $168 \mathrm{~h}$ time point/ $168 \mathrm{~h}$ from mixing). At each time point, the leachate of each specimen was collected for testing and replaced with $10 \mathrm{ml}$ of fresh deionized water to avoid liquid saturation.

\section{Calcium ion release measurement}

Calcium ion release was measured using Flame atomic absorption spectrophotometry (SavantAA AAS, GBC Scientific Equipment Pty Ltd., Victoria, Australia), utilizing a hollow, calcium cathode lamp, with the following technical parameters: a lamp current of $3 \mathrm{~mA}$, fuel used being acetylene, oxidant used being air; stoichiometry: reducing; a wavelength of $422.7 \mathrm{~nm}$, and a slit width of 0.5 $\mathrm{nm}$. All the glassware used in the experiment was washed using 5\% nitric acid before use to avoid interferences by phosphates and alkaline metals. The leachate was diluted in deionized water to allow the readability of the calcium ion release in cases when it was beyond device's reading limits. The calibration curve method, using standard solutions of calcium ions with deionized water as the calibration blank, was used for external calibration. The linear regression method, using the equation of the standard curve, was used to estimate the results.

\section{pH measurement}

The $\mathrm{pH}$ of the leachate was measured as a surrogate of the alkalizing activity of each material. The leachate was shaken for $5 \mathrm{sec}$ before $\mathrm{pH}$ measurement using a digital pH-meter (Thermo Scientific Orion Versa Star, Thermo Fisher Inc., MA, USA) that was calibrated beforehand using standard buffer solutions with $\mathrm{pH} 4.0, \mathrm{pH} 7.0$ and $\mathrm{pH} 11.0$ at room temperature. The electrode was rinsed with deionized water then blot dried before every measurement.

\section{Statistical Analysis}

Data were analysed using two-way analysis of variance (ANOVA) with repeated measures to assess the effect of the following variables: Group (DW, CL, NaP and CA), Time (24h, 72h and 168h), and the interaction between them [Group*Time] on calcium ion release and $\mathrm{pH}$. One-way ANOVA with repeated measures was used to assess the effect of time on $\mathrm{pH}$ and calcium ion release for each group separately. Comparison among groups at each time point was done using one-way ANOVA followed by Tukey post hoc test for multiple comparisons. Cumulative values of calcium ion release were obtained by adding the calcium ion release of each specimen at each time point and the preceding ones i.e. cumulative value at $72 \mathrm{~h}$ comprises ion release at $72 \mathrm{~h}$ added to that at $24 \mathrm{~h}$, and cumulative value at $168 \mathrm{~h}$ comprises ion release at $168 \mathrm{~h}$ added to that at $72 \mathrm{~h}$ and $24 \mathrm{~h}$; comparing groups was done using oneway ANOVA followed by Tukey post hoc test for multiple comparisons. The statistical significance level $(\alpha)$ was set at 0.05 . Statistical analysis was done using SPSS version 21.0 software (IBM Corp., Armonk, NY, USA). 


\section{RESULTS}

\section{Calcium ion release measurement}

The mean and standard deviation values of the released calcium ion concentrations (in ppm) are presented in Table 1 and changes over time are illustrated in Figure 1.

There was a statistically significant effect of Group, Time and their interaction [Group*Time] ( $p=0.000$ for each). There was a statistically significant effect of time on calcium ion release within each group $(p<0.001)$. For both the $\boldsymbol{D W}$ and $\boldsymbol{C} \boldsymbol{L}$ groups, there was a statistically significant decrease from $24 \mathrm{~h}$ to $72 \mathrm{~h}(p<0.05)$, yet, there was no statistically significant difference from $72 \mathrm{~h}$ to $168 \mathrm{~h}$ ( $p>0.05$ ). For the $\boldsymbol{C A}$ group, there was a statistically significant, time-dependent decrease in calcium ion release over time $(p<0.05)$. For the $\mathrm{NaP}$ group, there was a statistically significant rise in calcium ion release from $24 \mathrm{~h}$ to $72 \mathrm{~h}(p<0.05)$, yet, there was no statistically significant difference from $72 \mathrm{~h}$ to $168 \mathrm{~h}(p>0.05)$.

At $24 \mathrm{~h}$, the order of calcium ion release of the different groups, in a descending order, was as follows: $\boldsymbol{C L}>\boldsymbol{C A}>\boldsymbol{D W}>\boldsymbol{N a P}$; there was a statistically significant difference within every group pair $(p<0.001)$. At $72 h$, the order of calcium ion release values of the different groups, in a descending order, was as follows: $\boldsymbol{C L}>\boldsymbol{N a P}>\boldsymbol{C A}$ $>\boldsymbol{D W}$; there was a statistically significant difference within the following group pairs: $\boldsymbol{C L}-\boldsymbol{C A}, \boldsymbol{C L}$ $D W$, and $\mathbf{N a P}-\mathbf{D W}(p<0.05)$. At $168 h$, the order of calcium ion release of the different groups, in a descending order, was as follows: $N \boldsymbol{a P}>\boldsymbol{C L}>\boldsymbol{C A}$ $>D W$; there was a statistically significant difference within all group pairs $(p<0.05)$ except $\boldsymbol{C A}-\boldsymbol{D W}$ $(p>0.05)$.

Regarding cumulative calcium ion release at $72 \mathrm{~h}$ (Table 1), the order of calcium ion release of the different groups, in a descending order, was as follows: $\boldsymbol{C L}>\boldsymbol{C A}>\boldsymbol{D W}>\boldsymbol{N a P}$; there was a statistically significant difference within every group pair $(p<0.001)$. Regarding cumulative calcium ion release at $168 \mathrm{~h}$ (Table 1), the order of calcium ion release of the different groups, in a descending order, was as follows: $\boldsymbol{C L}>\boldsymbol{C A}>\boldsymbol{D W}>\boldsymbol{N a P}$; there was a statistically significant difference within all group pairs $(p<0.05)$ except $\boldsymbol{D W}$-NaP $(p>0.05)$.

\section{pH measurement}

The mean and standard deviation values of $\mathrm{pH}$ are presented in Table 1 and changes over time are illustrated in Figure 2.

There was a statistically significant effect of Group, Time and their interaction [Group*Time] ( $p=0.000$ for each). There was a statistically significant effect of time on the $\mathrm{pH}$ level within each group $(p<0.005)$. For the $\boldsymbol{D} \boldsymbol{W}$ group, there was a statistically significant, time-dependent decrease in $\mathrm{pH}$ over time $(p<0.05)$. For the $\boldsymbol{C} \boldsymbol{L}$ group, there was a statistically significant decrease in $\mathrm{pH}$ from $24 \mathrm{~h}$ to $72 \mathrm{~h}(p<0.05)$ followed by a statistically significant rise from $72 \mathrm{~h}$ to $168 \mathrm{~h}(p<0.05)$. For both the $\mathbf{N a P}$ and $\boldsymbol{C A}$ groups, there was a statistically significant decrease from $24 \mathrm{~h}$ to $72 \mathrm{~h}(p<0.05)$, yet there was no statistically significant difference from $72 \mathrm{~h}$ to $168 \mathrm{~h}$ $(p>0.05)$.

At $24 \mathrm{~h}$, the order of $\mathrm{pH}$ values of the different groups, in a descending order, was as follows: $\mathbf{N a P}$ $>\boldsymbol{C A}>\boldsymbol{C L}>\boldsymbol{D W}$; there was a statistically significant difference within the following group pairs: $\mathbf{N a P}$ $\boldsymbol{C L}, \boldsymbol{N a P}-\boldsymbol{D W}$, and $\boldsymbol{C A}-\boldsymbol{D W}(p<0.05)$. At $72 h$, the order of $\mathrm{pH}$ values of the different groups, in a descending order, was as follows: $\boldsymbol{N a P}>\boldsymbol{C L}>\boldsymbol{D W}$ $>\boldsymbol{C A}$; there was a statistically significant difference within the following group pairs: $\mathrm{NaP}-\mathrm{CL}, \mathbf{N a P}$ $\boldsymbol{D W}$, and NaP-CA $(p<0.05)$. At $168 h$, the order of $\mathrm{pH}$ values of the different groups, in a descending order, was as follows: $\boldsymbol{C L}>\boldsymbol{N a P}>\boldsymbol{C A}>\boldsymbol{D W}$; there was a statistically significant difference within the following group pairs: $C L-C A, C L-D W, N a P-C A$, and $\boldsymbol{N a P}-\boldsymbol{D W}(p<0.05)$. 
TABLE (1) Calcium ion release, cumulative calcium ion release and $\mathrm{pH}$ values at the different time points (24h, 72h \& 168h).

\begin{tabular}{|c|c|c|c|c|}
\hline Time & $24 h$ & $72 \mathrm{~h}$ & $168 \mathrm{~h}$ & $p$-value ${ }^{\eta}$ \\
\hline Group & Mean (SD) & $\operatorname{Mean}(S D)$ & $\operatorname{Mean}(S D)$ & \\
\hline \multicolumn{5}{|c|}{ Calcium ion release } \\
\hline$D W$ & $7.17(1.07)^{\mathrm{c}, \mathrm{A}}$ & $4.11(0.37)^{\mathrm{c}, \mathrm{B}}$ & $3.68(0.21)^{\mathrm{c}, \mathrm{B}}$ & $<0.001$ \\
\hline$C L$ & $18.33(0.85)^{\mathrm{a}, \mathrm{A}}$ & $5.50(0.93)^{\mathrm{a}, \mathrm{B}}$ & $4.84(0.35)^{\mathrm{b}, \mathrm{B}}$ & $<0.001$ \\
\hline $\mathrm{NaP}$ & $3.59(0.39)^{\mathrm{d}, \mathrm{B}}$ & $5.33(0.30)^{\mathrm{a}, \mathrm{b}, \mathrm{A}}$ & $6.00(0.81)^{\mathrm{a}, \mathrm{A}}$ & $<0.001$ \\
\hline$C A$ & $11.17(1.08)^{\mathrm{b}, \mathrm{A}}$ & $4.71(0.47)^{\mathrm{b}, \mathrm{c}, \mathrm{B}}$ & $4.1(0.48)^{\mathrm{c}, \mathrm{C}}$ & $<0.001$ \\
\hline$p$-value* & $<0.001$ & $<0.001$ & $<0.001$ & \\
\hline \multicolumn{5}{|c|}{ Cumulative Calcium ion release } \\
\hline$D W$ & $7.17(1.07)^{\mathrm{c}}$ & $11.28(1.25)^{\mathrm{c}}$ & $14.96(1.35)^{\mathrm{c}}$ & \\
\hline$C L$ & $18.33(0.85)^{\mathrm{a}}$ & $23.83(1.43)^{\mathrm{a}}$ & $28.67(1.26)^{\mathrm{a}}$ & \\
\hline $\mathrm{NaP}$ & $3.59(0.39)^{\mathrm{d}}$ & $8.92(0.48)^{\mathrm{d}}$ & $14.93(1.22)^{\mathrm{c}}$ & \\
\hline$C A$ & $11.17(1.08)^{\mathrm{b}}$ & $15.88(1.09)^{\mathrm{b}}$ & $19.98(1.30)^{\mathrm{b}}$ & \\
\hline$p$-value* & $<0.001$ & $<0.001$ & $<0.001$ & \\
\hline \multicolumn{5}{|c|}{ pH } \\
\hline$D W$ & $9.60(0.12)^{\mathrm{c}, \mathrm{A}}$ & $9.13(0.10)^{\mathrm{b}, \mathrm{B}}$ & $8.83(0.08)^{\mathrm{b}, \mathrm{C}}$ & $<0.001$ \\
\hline$C L$ & $9.77(0.35)^{\mathrm{b}, \mathrm{c}, \mathrm{A}}$ & $9.10(0.09)^{\mathrm{b}, \mathrm{C}}$ & $9.67(0.13)^{\mathrm{a}, \mathrm{B}}$ & 0.003 \\
\hline $\mathrm{NaP}$ & $10.20(0.20)^{\mathrm{a}, \mathrm{A}}$ & $9.70(0.26)^{a, B}$ & $9.54(0.20)^{\mathrm{a}, \mathrm{B}}$ & 0.001 \\
\hline$C A$ & $10.03(0.06)^{\mathrm{a}, \mathrm{b}, \mathrm{A}}$ & $9.04(0.08)^{\mathrm{b}, \mathrm{B}}$ & $8.97(0.06)^{\mathrm{b}, \mathrm{B}}$ & $<0.001$ \\
\hline$p$-value* & $<0.001$ & $<0.001$ & $<0.001$ & \\
\hline
\end{tabular}

* designates p-values of one-way ANOVA test comparing groups per time point. " designates p-value of one-way ANOVA test with repeated measures comparing time points per group for $\mathrm{pH}$ and calcium ion release values. Different lower-case letters in columns designate statistically-significantly different groups per time point. Different upper-case letters in rows designate statistically-significantly different time points per group for $\mathrm{pH}$ and calcium ion release values. MTA groups according to vehicle: $\mathrm{DW}$, distilled water (control); $\mathrm{CL}, 5 \% \mathrm{CaCl}_{2} ; \mathrm{NaP}, 15 \% \mathrm{Na}_{2} \mathrm{HPO}_{4} ; \mathrm{CA}, 0.1 \%$ citric acid. SD, standard deviation.

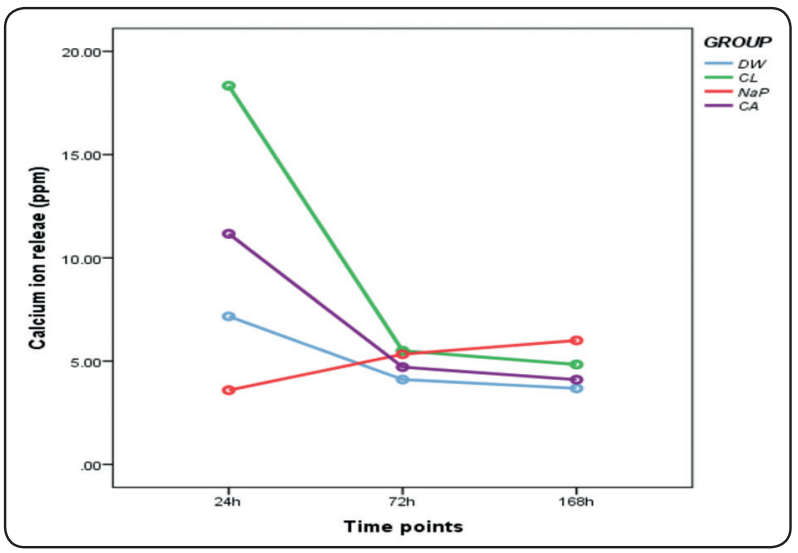

Fig. (1) Line chart showing the variations in calcium ion release among groups and within group over time $(24 \mathrm{~h}, 72 \mathrm{~h} \&$ 168h). MTA groups according to vehicle: DW, distilled water (Control); $\mathrm{CL}, 5 \% \mathrm{CaCl}_{2} ; \mathrm{NaP}, 15 \% \mathrm{Na}_{2} \mathrm{HPO}_{4}$; CA, $0.1 \%$ citric acid.

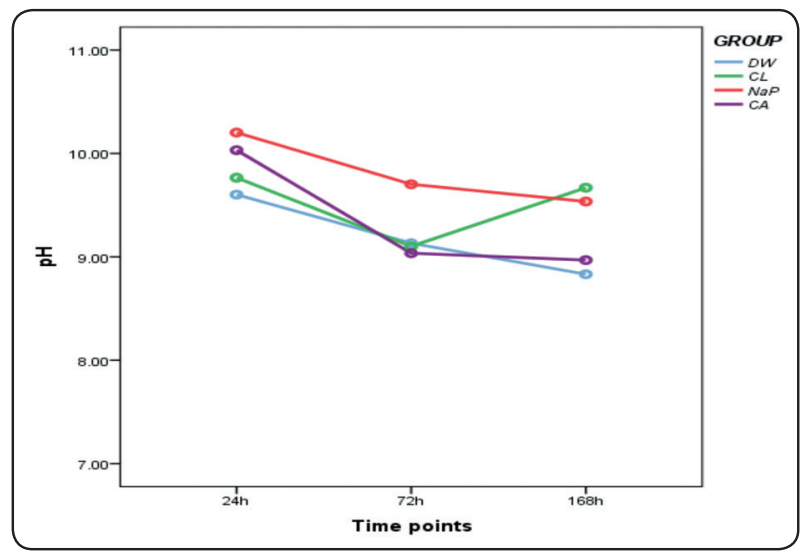

Fig. (2) Line chart showing $\mathrm{pH}$ variations among groups and within group over time (24h, $72 \mathrm{~h} \& 168 \mathrm{~h})$. MTA groups according to vehicle: DW, distilled water (Control); CL, $5 \% \mathrm{CaCl}_{2} ; \mathrm{NaP}, 15 \% \mathrm{Na}_{2} \mathrm{HPO}_{4} ; \mathrm{CA}, 0.1 \%$ citric acid. 


\section{DISCUSSION}

Despite the many advantages of MTA, a few shortcomings still exist among which is its long setting time ${ }^{(1)}$. Several accelerants have been used with MTA ${ }^{(1,20,21)}$; few studies, however, have assessed their effects on the biointeractivity of the material $(15,13,23)$. The use of additives within the composition of CSCs can affect their properties. ${ }^{(21,28,30)}$. Assessing the physicochemical interaction of MTA with the environment when mixed with different accelerant solutions as vehicles could help clarify their mechanisms of action on various clinical applications where favourable cellular response, hard-tissue-forming ability and antibacterial activity are required; this could enhance clinical success through biological seal and local infection control $^{(3,8,27)}$.

The alkalizing activity of MTA has several biological effects. It provides antimicrobial and anti-inflammatory activity $(1,4,5,8,10)$. The hydroxyl ions act against microbes, especially bacteria, through destroying their cytoplasmic membranes, denaturing their proteins, preventing microbial regrowth and neutralizing lactic acid produced during bacterial activity ${ }^{(10)}$. The alkaline $\mathrm{pH}$, also, enhances the release of enzymes, e.g. alkaline phosphatase and metalloproteinases, and growth factors, e.g. bonemorphogenetic protein 2 (BMP-2), essential for mineralization from the dentin matrix stimulating migration, proliferation and differentiation of hardtissue-forming cells and has a caustic effect on connective tissue (pulpal/periapical) triggering its repair ${ }^{(3,4,5,8,31)}$.

Calcium ion release is important for the viability, growth and differentiation of hard-tissue-forming cells, e.g. dental pulp cells and osteoblasts, leading to dentin mineralization and the formation of hard-tissue barriers ${ }^{(10,15,28)}$; it is, also, involved in the elimination of environmental carbon dioxide necessary for bacterial growth ${ }^{(10)}$. Regenerative/ reparative processes are actualized through the role of calcium ions in the enhancement of cell proliferation, the modulation of mineralization- related growth factors, e.g. osteopontin $(\mathrm{OPN})$ and BMP-2, and the stimulation of pyrophosphatase activity $(4,5,10,15,27,32)$. The ability of MTA to stimulate hard-tissue formation has been attributed to its bioactivity i.e. ability to form apatite ${ }^{(4,6)}$. Released calcium ions interact with phosphate radicles/ions from the surrounding tissue fluids in an alkalizing medium forming apatite-like precipitation on the surface of MTA in situ; such bioactivity enhances cell proliferation and hard-tissue-forming cell differentiation as well as reduces dentin permeability if deposited in dentinal tubules ${ }^{(3,4,5,10,27,33,34)}$.

Reducing the setting time of the MTA improves its handling in clinical application ${ }^{(19)}$. Several accelerants to MTA have been investigated including: $\mathrm{CaCl}_{2}$, in powder or solution forms, calcium lactate gluconate (CLG) solution, low-dose citric acid, calcium formate, calcium nitrite/nitrate, $\mathrm{Na}_{2} \mathrm{HPO}_{4}$ and polycarboxylate ${ }^{(9,13,16-19,24)} \cdot \mathrm{CaCl}_{2}$ has been the most-commonly used MTA accelerant ${ }^{(9}$, 20, 21, 24) which improved MTA's handling properties with less need for water of hydration, allowed better MTA sealing on retrofilling, and increased MTA's ability to induce osteoblast differentiation through enhancing calcium release ${ }^{32,27)}$; its addition, however, may jeopardize MTA's mechanical properties ${ }^{(12,16,19,21,23)}$. $\mathrm{Na}_{2} \mathrm{HPO}_{4}$ in solution is used as a buffer and has been shown to be an effective MTA accelerant that may improve its biocompatibility and bond strength to dentin without adversely affecting its mechanical properties ${ }^{(17,18,35,36)}$. A low concentration of citric acid $(0.1 \%)$ has been, also, explored as an MTA accelerant ${ }^{(19)}$; concentrations more the $0.1 \%$, however, are retarders ${ }^{(37)}$. To standardize the accelerant form, all the accelerants in the present study were used as solutions. The $5 \% \mathrm{CaCl}_{2}$ concentration was selected as it was as effective as $10 \% \mathrm{CaCl}_{2}$ powder in shortening the setting time of MTA by at least $50 \%{ }^{(13,16)}$ as well as being the most-commonly-studied solution concentration $(9,16,30)$.

In the present study, using $5 \% \mathrm{CaCl}_{2}$ solution as vehicle significantly increased the calcium ion 
release of MTA and caused a 'late' (after 7 days) rise in the leachate $\mathrm{pH}$ of MTA. This is agreement with previous studies ${ }^{(13,15)}$, yet, in disagreement with others ${ }^{(9,19,23)}$. Bortoluzzi et al. ${ }^{(13)}$ reported a rise in the leachate $\mathrm{pH}$ of MTA with $10 \% \mathrm{CaCl}_{2}$ powder within the first $24 \mathrm{~h}$ contrary to the 'later' rise in the present study. Wiltbank et al. showed that the use of $5 \% \mathrm{CaCl}_{2}$ solution as vehicle did not affect the pH of MTA mix ${ }^{(9)}$. Other studies showed that the addition of $10 \% \mathrm{CaCl}_{2}$ powder to MTA decreased the $\mathrm{pH}$ of MTA mix ${ }^{(19)}$ and leachate ${ }^{(23)}$. Variations among studies could be attributed to differences in the form and concentration of the $\mathrm{CaCl}_{2}$ used and the study methodology. The higher calcium ion release of Biodentine than MTA has been partly attributed to its $\mathrm{CaCl}_{2}$ content leading to its higher content of calcium hydroxide ${ }^{(4,27,28,30)}$. Using $5 \%$ $\mathrm{CaCl}_{2}$ increased the amount of calcium hydroxide produced within MTA which was at its maximum at 8 hours and that was earlier than that of MTA alone reaching its maximum in 1 week to 1 month ${ }^{(30,38)}$; this has been explained, at least in part, on the basis of the penetration of of $\mathrm{CaCl}_{2}$ into the cement pores causing significant acceleration of its hydration with faster crystallization ${ }^{(13,19)}$.

The use of $15 \% \mathrm{Na}_{2} \mathrm{HPO}_{4}$ as a vehicle did not seem to affect MTA's overall calcium ion release despite an early (at 24h) lowered release; yet, it elevated the leachate's $\mathrm{pH}$ which was sustainable throughout the experimental duration of 7 days. Findings about $\mathrm{pH}$ are in accordance with a previous study ${ }^{(23)}$, yet, in disagreement with others where the vehicle did not influence MTA's $\mathrm{pH}^{(17,18)}$; in the latter two studies, however, the $\mathrm{pH}$ of the cement mix rather than the leachate was measured within a span of 60 minutes after which setting progresses that $\mathrm{pH}$ measurement is not applicable ${ }^{(17,18)}$. No studies have, yet, been detected that assessed calcium ion release on using $\mathrm{Na}_{2} \mathrm{HPO}_{4}$ solution as vehicle. The $\mathrm{pH}$ of the $15 \%$ $\mathrm{Na}_{2} \mathrm{HPO}_{4}$ is inherently alkaline being $9.5^{(17)}$. In the presence of a source of phosphate ions, regardless of its nature or form, calcium hydroxide reacts with the phosphate ions producing biomimetic calcium phosphates (e.g. hydroxyapatite or hydroxypatitelike phases) through strong ionic interactions between phosphate as anion and calcium and/or silicates as cations $(3,5,6,17,18,25,26,33,34)$. This could explain the early consumption of calcium ions into such reaction with less available calcium ions in the leachate and the release of the replaced sodium ions from the mixture into the deionized water could have led to the sustained rise in its $\mathrm{pH}$. Better biomineralization and less connective tissue inflammation in contact with MTA incorporating $\mathrm{Na}_{2} \mathrm{HPO}_{4}$ has been attributed to the more rapid bioactivity of MTA ${ }^{(35,36)}$.

With $0.1 \%$ citric acid as a vehicle for MTA, an early (at 24h) increase in $\mathrm{pH}$ and calcium ion release, influencing the overall calcium ion release, compared to MTA alone. This disagrees with a previous study where low-dose citric acid decreased the $\mathrm{pH}$ of MTA mixture; this has been rendered to the acidity of the solution ${ }^{(19)}$. Differences in findings between studies could be explained on the basis of the differences in the method of preparation of the specimens, with the different exposed surface areas (ESAs) ${ }^{(28)}$ and the different soaking liquids. Acceleration or retardation effects of citric acid have been explained on the basis of their effects on the calcium hydroxide content produced within the cement, electrical conductivity as well as the concentration and speed of anions and cations ${ }^{(19,37)}$.

All MTA mixtures, in this study, exhibited a significant decrease in calcium ion release from $24 \mathrm{~h}$ to 72 which continued at a less rate up to 7 days except for the MTA mixture with $15 \% \mathrm{Na}_{2} \mathrm{HPO}_{4}$ solution where ion release increased significantly after $72 \mathrm{~h}$ which was sustained up to 7 days. The first finding is in accordance with previous studies where CSCs show a decrease in calcium ion release over time ${ }^{(29,26,27,4,28)}$. This has been attributed to the slowing in the hydration reaction over time ${ }^{(29)}$ with a slower rate of formation of calcium hydroxide being the source of calcium ions. A previous study, however, has revealed a decrease in calcium ion release over time with calcium silicate/ 
calcium phosphate combinations ${ }^{(5)}$. The variation in results between studies could be attributed to the differences in type and form of the phosphate compound used. Gandolfi et al. ${ }^{(5)}$ used $\alpha$-tricalcium phosphate or dicalcium phosphate dihydrate (DCPD) as sources of phosphate; both compounds, also, contain calcium which could justify their initially-high calcium ion level. No previous studies have assessed the effect of $15 \% \mathrm{Na}_{2} \mathrm{HPO}_{4}$ solution as a vehicle on MTA calcium ion release as in the present study. The affinity of the reaction between the released phosphate ions and calcium ions from the dissociation of the calcium hydroxide produced during MTA hydration to form a calcium phosphate form e.g. apatite-like compounds that is responsible for the bioactivity of CSCs ${ }^{(5,25)}$ could cause an initial consumption of the released calcium ions causing their initial lower level in the leachate which increases later as the MTA hydration reaction continues to produce more calcium hydroxide within its bulk that leach out into the surrounding environment. A previous study on Endosequence BC sealer, a biphasic calcium silicate-based sealer containing monobasic calcium phosphate, reported a lower calcium ion release for this sealer compared to MTA and Biodentine; this was rendered, in part, to the consumption of the produced calcium hydroxide in the formation of an apatite phase in bulk ${ }^{(26)}$. Another study has explained the decreased inflammation in contact with MTA mixed with $\mathrm{Na}_{2} \mathrm{HPO}_{4}$ in light of the reaction of $\mathrm{Na}_{2} \mathrm{HPO}_{4}$ with calcium hydroxide creating hydroxyapatite within the bulk and on the surface of MTA even before subcutaneous implantation ${ }^{(35)}$.

Regarding the variation in $\mathrm{pH}$ over time, findings revealed an alkalizing activity for all the mixtures used in the present study to their leachates with a decrease in $\mathrm{pH}$ over the experimental duration for all MTA mixtures except when $5 \% \mathrm{CaCl}_{2}$ was used as the vehicle, where an initial decrease in $\mathrm{pH}$ occurred from $24 \mathrm{~h}$ to $72 \mathrm{~h}$ followed by a rise in $\mathrm{pH}$ from $72 \mathrm{~h}$ to 7 days. The first finding is in accordance with most studies in the literature ${ }^{(4,13,29,27,28)}$. The
$\mathrm{pH}$ trend with the $\mathrm{CaCl}_{2}$ accelerant agreed with that reported by a previous study ${ }^{(27)}$, yet, disagreed with others ${ }^{(4,13)}$. Dawood et al. reported a rise in the leachate $\mathrm{pH}$ between 3 and 7 days with Biodentine, containing $\mathrm{CaCl}_{2}$ as accelerant, but at 14 days with MTA Angelus. Findings by Bortoluzzi et al. ${ }^{(13)}$ and Gandolfi et al. ${ }^{(4)}$, however, showed a decreasing $\mathrm{pH}$ trend from 1 to 7days. Variations among studies' findings could be attributed to differences in the form and concentration $\mathrm{CaCl}_{2}$ and study methodology including methods of preparing leachates and the ESA which could affect ion-leaching kinetics ${ }^{(4,13,28)}$.

Basically, hydration of MTA involves a reaction of its main components, usually tricalcium silicate and dicalcium silicate, with water mainly producing calcium-silicate hydrate and calcium hydroxide which dissociates into calcium and hydroxyl ions in the presence of water ${ }^{(3,7,13)}$. This reaction continues well beyond its apparent setting in a maturation process that could take years ${ }^{(38)}$. Variations in the biointeractivity of different cements and over time have been rendered to differences in their chemical composition and rate of formation of calcium hydroxide ${ }^{(27)}$. The general trend of decreasing biointeractivity over time has been explained on the basis of the slowing down of the reaction rate with time resulting in less ion release ${ }^{(29,27)}$. Differential scanning calorimetry (DSC) studies have shown that that calcium hydroxide amounts fluctuate within the hydrated cement over time ${ }^{(30,38)}$. Calcium hydroxide content was found to reach its maximum in 1 week to 1 month ${ }^{(30,38)}$ after which, content reduction occurs; such reduction has been rendered to carbonation, conversion of calcium hydroxide to calcium carbonate through a reaction with atmospheric carbon dioxide ${ }^{(30,38)}$. The $\mathrm{pH}$ of $\mathrm{CaCl}_{2}$ solution is acidic $(\mathrm{pH}=4.4)^{(15)} \cdot \mathrm{CaCl}_{2}$ has been shown to reduce the $\mathrm{pH}$ of aqueous phase in hydrating tricalcium silicate $^{(13,19,23)}$; this was explained on the basis of the diffusion coefficient of chloride ions $\left(\mathrm{Cl}^{-}\right)$in the cement mixture which was found to be greater than the cations in the cement suggesting a counter 
diffusion between $\mathrm{Cl}^{-}$and hydroxyl ions $\left(\mathrm{OH}^{-}\right)$so that the later would rapidly react with calcium ions forming calcium hydroxide in the surface layer of calcium silicate hydrate of the tricalcium silicate particles ${ }^{(39)}$. This could be explained in light of 'Le Chatelier's principle' according to which the addition of calcium-based electrolytes, e.g. $\mathrm{CaCl}_{2}$, to accelerate MTA's hydration tends to decrease the ionization of calcium hydroxide, thus, the leachate's $\mathrm{pH}$ could be lowered due to the common-ion effect ${ }^{(40)}$. It has been suggested that the $\mathrm{pH}$ fluctuations among different cements and with each cement over time may not influence MTA's antimicrobial activity ${ }^{(23)}$.

Considering the conditions in this study, it could be concluded that accelerant vehicles to MTA can differentially affect its biointeractivity. Using 5\% $\mathrm{CaCl}_{2}$ can significantly enhance MTA's supply of calcium ions into the environment early on (within the first 24h). On the other hand, using $15 \% \mathrm{Na}_{2} \mathrm{H}-$ $\mathrm{PO}_{4}$ could enhance the alkalizing activity of MTA over the first 7 days. Low-dose $(0.1 \%)$ citric acid can provide an early, moderate rise in both the calcium ion release capability and alkalizing activity of MTA. The clinical significance of such biointeractive qualities, however, is yet to be investigated.

\section{REFERENCES}

1. Parirokh M, Torabinejad M. Mineral trioxide aggregate: A comprehensive literature review- Part I: Chemical, physical, and antibacterial properties. J Endod 2010; 36: 16-27.

2. Parirokh M, Torabinejad M. Mineral trioxide aggregate: A comprehensive literature review- Part III: Clinical applications, drawbacks, and mechanism of action. J Endod 2010; 36: 400-13.

3. Sarkar NK, Caicedo R, Ritwik P, Moiseyeva R, Kawashima I. Physicochemical basis of the biological properties of mineral trioxide aggregate. J Endod 2005; 31: 97-100.

4. Gandolfi MG, Siboni F, Botero T, Bossù M, Riccitiello F, Prati C. Calcium silicate and calcium hydroxide materials for pulp capping: biointeractivity, porosity, solubility and bioactivity of current formulations. J Appl Biomater Funct Mater 2015; 13: 43-60.
5. Gandolfi MG, Spagnuolo G, Siboni F, Procino A, Rivieccio V, Pelliccioni GA, Prati C, Rengo S. Calcium silicate/ calcium phosphate biphasic cements for vital pulp therapy: chemical - physical properties and human pulp cells response. Clin Oral Investig 2015; 19: 2075-89.

6. Gandolfi MG, Taddei P, Tinti A, Prati C. Apatite-forming ability (bioactivity) of ProRoot MTA. Int Endod J 2010; 43: 917-29.

7. Camilleri J. Characterization of hydration products of mineral trioxide aggregate. Int Endod J 2008; 41: 408-17.

8. Okiji T, Yoshiba K. Reparative dentinogenesis induced by mineral trioxide aggregate: a review from the biological and physicochemical points of view. Int J Dent 2009; 2009: 464280 .

9. Wiltbank KB, Schwartz SA, Schindler WG. Effect of selected accelerants on the physical properties of mineral trioxide aggregate and Portland cement. J Endod 2007; 33: 1235-8

10. Gandolfi MG. A new method for evaluating the diffusion of $\mathrm{Ca}^{2+}$ and $\mathrm{OH}^{-}$through coronal dentin into the pulp. Iran Endod J 2012; 7: 189-97.

11. Guimarães BM, Vivan RR, Piazza B, Alcalde MP, Bramante CM, Duarte MAH. Chemical-physical properties and apatite-forming ability of mineral trioxide aggregate Flow. J Endod 2017; 43: 1692-6.

12. Ber BS, Hatton JF, Stewart GP. Chemical modification of ProRoot MTA to improve handling characteristics and decrease setting time. J Endod 2007; 33: 1231-4.

13. Botoluzzi EA, Broon NJ, Bramante CM, Felippe WT, Tanomaru Filho M, Esberard RM. The influence of calcium chloride on the setting time, solubility, disintegration, and $\mathrm{pH}$ of mineral trioxide aggregate and white Portland cement with a radiopacifier. J Endod 2009; 35: 550-4.

14. Lee YL, Lee BS, Lin FH, Yun Lin A, Lan WH, Lin CP. Effects of physiologic environments on the hydration behavior of mineral trioxide aggregate. Biomaterials 2004; 25: 787-93.

15. Antunes Bortoluzzi E, Juárez Broon N, Antonio Hungaro Duarte M, de Oliveira Demarchi AC, Monteiro Bramante C. The use of a setting accelerator and its effect on $\mathrm{pH}$ and calcium ion release of mineral trioxide aggregate and white Portland cement. J Endod 2006; 32: 1194-7.

16. Kogan P, He J, Glickman GN, Watanabe I. The effects of various additives on setting properties of MTA. J Endod 2006; 32: 569-72. 
17. Huang TH, Shie MY, Kao CT, Ding SJ. The effect of setting accelerator on properties of mineral trioxide aggregate. J Endod 2008; 34: 590-3.

18. Ding SJ, Kao CT, Shie MY, Hung C Jr, Huang TH. The physical and cytological properties of white MTA mixed with $\mathrm{Na}_{2} \mathrm{HPO}_{4}$ as an accelerant. J Endod 2008; 34: 748-51.

19. Lee BN, Hwang YC, Jang JH, Chang HS, Hwang IN, Yang SY, Park YJ, Son HH, Oh WM. Improvement of the properties of mineral trioxide aggregate by mixing with hydration accelerators. J Endod 2011; 37: 1433-6.

20. Altan H, Tosun G. The setting mechanism of mineral trioxide aggregate. J Istanbul Uni Fac Dent 2016; 50: 65-72.

21. Saghiri MA, Orangi J, Asatourian A, Gutmann JL, GarciaGodoy F, Lotfi M, Sheibani N. Calcium silicate-based cements and functional impacts of various constituents. Dent Mater J 2017; 36: 8-18.

22. Bortoluzzi EA, Broon NJ, Bramante CM, Garcia RB, de Moraes IG, Bernardineli N. Sealing ability of MTA and radiopaque Portland cement with and without calcium chloride for root-end filling. J Endod 2006; 32: 897-900.

23. Prasad A, Pushpa S, Arunagiri D, Sawhny A, Misra A, Sujatha R. A comparative evaluation of the effect of various additives on selected physical properties of white mineral trioxide aggregate. J Conserv Dent 2015; 18: 237-41.

24. Ahmed HMA, Luddin N, Kannan TP, Mokhtar KI, Ahmad A. White mineral trioxide aggregate mixed with calcium chloride dihydrate: chemical analysis and biological properties. Restor Dent Endod 2017; 42: 176-87.

25. Camilleri J, Cutajar A, Mallia B. Hydration characteristics of zirconium oxide replaced Portland cement for use as a root-end filling material. Dent Mater 2011; 27: 845-54.

26. Han L, Okiji T. Bioactivity evaluation of three calcium silicate-based endodontic materials. Int Endod J 2013; 46: 808-14.

27. Dawood AE, Manton DJ, Parashos P, Wong R, Palamara J, Stanton DP, Reynolds EC. The physical properties and ion release of CPP-ACP-modified calcium silicate-based cements. Aust Dent J 2015; 60: 434-44.

28. Rajasekharan S, Vercruysse C, Martens L, Verbeeck R. Effect of exposed surface area volume and environment $\mathrm{pH}$ on the calcium ion release of three commercially available tricalcium silicate based dental cements. Materials (Basel) 2018; 11: doi: 10.3390/ma11010123.
29. Vivan RR, Zapata RO, Zeferino MA, Bramante CM, Bernardineli N, Garcia RB, Hungaro Duarte MA, Tanomaru Filho M, Gomes de Moraes I. Evaluation of the physical and chemical properties of two commercial and three experimental root-end filling materials. Oral Surg Oral Med Oral Pathol Oral Radiol Endod 2010; 110: 250-6.

30. Zapf AM, Chedella SC, Berzins DW. Effect of additives on mineral trioxide aggregate setting reaction product formation. J Endod 2015; 41: 88-91.

31. Torabinejad M, Parirokh M. Mineral trioxide aggregate: A comprehensive literature review- Part II: leakage and biocompatibility investigations. J Endod 2010; 36: 190-202.

32. Matsumoto S, Hayashi M, Suzuki Y, Suzuki N, Maeno M, Ogiso B. Calcium ions released from mineral trioxide aggregate convert the differentiation pathway of $\mathrm{C} 2 \mathrm{C} 12$ cells into osteoblast lineage. J Endod 2013; 39: 68-75.

33. Tay FR, Pashley DH, Rueggeberg FA, Loushine RJ, Weller RN. Calcium phosphate phase transformation produced by the interaction of the Portland cement component of white mineral trioxide aggregate with a phosphate-containing fluid. J Endod 2007; 33: 1347-51.

34. Ding SJ, Shie MY, Wang CY. Novel fast-setting calcium silicate bone cements with high bioactivity and enhanced osteogenesis in vitro. J Mate Chem 2009; 19: 1183-90.

35. Lotfi M, Vosoughhosseini S, Saghiri MA, Mesgariabbasi M, Ranjkesh B. Effect of white mineral trioxide aggregate mixed with disodium hydrogen phosphate on inflammatory cells. J Endod 2009; 35: 703-5.

36. Mokhtari H, Jafarizadeh S, Mokhtari Zonouzi HR, Lotfi M, Forough Reyhani M, Sohrabi A. Bond strength of white mineral trioxide aggregate with and without disodium hydrogen phosphate with different liquid-to-powder ratios. Iran Endod J 2017; 12: 293-7.

37. Singh NB, Singh AK, Singh SP. Effect of citric acid on the hydration of Portland cement. Cem Concr Res 1986; 16: $911-20$

38. Chedella SC, Berzins DW. A differential scanning calorimetry study of the setting reaction of MTA. Int Endod J 2010; 43: 509-18.

39. Kondo R, Daimon M, Sakai E, Ushiyama H. Influence of inorganic salts on the hydration of tricalcium silicate. J Appl Chem Biotechnol 1977; 27: 191-7.

40. Ji DY, Wu HD, Hsieh SC, Teng NC, Chen CC, Ke ES, Lin YC, Lee SY, Yang JC. Effects of a novel hydration accelerant on the biological and mechanical properties of white mineral trioxide aggregate. J Endod 2011; 37: 1433-6. 